\title{
Predictive biomarkers for combined chemotherapy with 5-fluorouracil and cisplatin in oro- and hypopharyngeal cancers
}

\author{
YASUHISA HASEGAWA $^{1}$, MITSUO GOTO ${ }^{2}$, NOBUHIRO HANAI ${ }^{1}$, TAIJIRO OZAWA ${ }^{3}$ and HITOSHI HIRAKAWA ${ }^{4}$ \\ ${ }^{1}$ Department of Head and Neck Surgery, Aichi Cancer Center Hospital, Chikusaku, Nagoya 464-8681; \\ ${ }^{2}$ Department of Maxillofacial Surgery, Aichi Gakuin University, Chikusaku, Nagoya 464-8650; \\ ${ }^{3}$ Department of Otorhinolaryngology, Toyohashi Municipal Hospital, Aotakecho, Toyohashi 441-8570; \\ ${ }^{4}$ Department of Otorhinolaryngology, Head and Neck Surgery, Graduate School of Medicine, \\ University of The Ryukyus, Nishiharacho, Okinawa 903-0215, Japan
}

Received September 6, 2017; Accepted November 27, 2017

DOI: $10.3892 / \mathrm{mco} .2017 .1521$

\begin{abstract}
The present study aimed to identify significant correlations between gene expression and chemotherapy response to 5-fluorouracil (5-FU)/cisplatin in head and neck squamous cell carcinoma (HNSCC), and to identify patients who would benefit from induction chemotherapy for both organ preservation and survival. A total of 64 patients who underwent radical treatment for HNSCC were enrolled. All patients received induction chemotherapy with 5-FU/cisplatin and tumor responses were evaluated. Pretreatment biopsy specimens from all patients were assayed for mRNA
\end{abstract}

Correspondence to: Dr Yasuhisa Hasegawa, Department of Head and Neck Surgery, Aichi Cancer Center Hospital, 1-1 Kanokoden, Chikusaku, Nagoya 464-8681, Japan

E-mail: hasegawa@aichi-cc.jp

Abbreviations: 5FU, 5-fluorouracil; Bcl-2, b-cell lymphoma 2; Bcl-xL, b-cell lymphoma-extra large; CI, confidence interval; COX2, cyclooxygenase-2; CR, complete response; CT, computed tomography; CT, threshold cycle; DPD, dihydropyrimidine dehydrogenase; EGFR, epidermal growth factor receptor; ENT1, equilibrative nucleoside transporter 1; ERCC1, excision repair cross-complementing 1; GAPDH, glyceraldehyde 3-phosphate dehydrogenase, GST-pi, glutathione S-transferase-pi; HDRA, histoculture drug response assay; HER2, human epidermal growth factor receptor 2; HNSCC, head and neck squamous cell carcinoma; MDR1, multidrug resistance gene 1; MRP1, multidrug resistance-associated protein 1; NER, nucleotide excision repair; OPRT, orotate phosphoribosyltransferase; OR, odds ratios; PI3K, phosphoinositide 3-kinase; PR, partial response; PTEN, phosphatase and tensin homolog; RECIST, response evaluation criteria In solid tumor guidelines; RT-PCR, reverse Transcription-PCR; TP, tymidine phosphorylase; TS, thymidylate synthase; UICC, union for international cancer control; VEGF, vascular endothelial growth factor

Key words: biomarkers, chemotherapy, head and neck cancer, ERCC1, p53 expression of thymidylate synthase, dihydropyrimidine dehydrogenase (DPD), orotate phosphoribosyltransferase, tymidine phosphorylase, glutathione S-transferase-pi, p53, RB Transcriptional Corepressor 1, B-cell lymphoma 2 (Bcl-2), Bcl-xL, E2F Transcription Factor 1, epidermal growth factor receptor, human epidermal growth factor receptor 2, phosphoinositide 3-kinase, phosphatase and tensin homolog, vascular endothelial growth factor (VEGF), cyclooxygenase-2, XPA, DNA Damage Recognition And Repair Factor, excision repair cross-complementing 1 (ERCC1), multidrug resistance gene 1 (MDR1), multidrug resistance-associated protein 1 , equilibrative nucleoside transporter 1 and $\beta$-tubulin by reverse transcription-quantitative polymerase chain reaction, and the association between the expression levels of these genes and patient response to chemotherapy was determined. The complete response (CR) group and non-CR group for induction chemotherapy comprised 32.8 and $67.2 \%$ of patients, respectively. The 5-year overall survival rate was significantly higher for the CR group (95\%) compared with the non-CR group (57\%). According to univariate analysis, chemotherapy response was associated with T-class and mRNA expressions of DPD, ERCC1, XPA, p53, Bcl-2, VEGF and MDR1. Multivariate analysis identified ERCC1 expression and T-class as significant predictors of response to chemotherapy, indicating that a DNA-repair pathway and apoptosis pathway are pivotal mechanisms governing response to chemotherapy. The findings suggest that ERCC1 expression could be a predictive biomarker for chemotherapy response to 5-FU/cisplatin in HNSCC. Assessing mRNA expression is a standard method for these studies, however further investigations examining polymorphisms and mutations in addition to apoptotic responses are required to determine target gene activation in HNSCC.

\section{Introduction}

Head and neck squamous cell carcinoma (HNSCC) is highly sensitivity to anticancer agents. Various types of agents have been studied for the treatment of HNSCC. Recently, new agents designed to target specific molecular defects unique to the cancer have been developed. However, combination chemotherapy with 5-fluorouracil (5-FU) and cisplatin is still the most 
common regimen for HNSCC, showing major response rates of $60-90 \%$ and complete response (CR) rates of $20-50 \%(1,2)$. Patients with CR or partial response (PR) show improved survival, while those with no response show no improvements in either organ preservation or survival. However, the optimal chemotherapy regimen and the role of induction chemotherapy and adjuvant chemotherapy remain unclear. Moreover, there is currently no promising way to assess a patient's response to chemotherapy or to identify patients who are sensitive to individual anticancer agents. Drug resistance, especially in patients with recurrent and metastatic disease, may be a major factor in preventing favorable outcomes in HNSCC patients. Therefore, identification of patients who respond to chemotherapy can help to develop specifically tailored therapies to enhance survival rates and quality of life. One clinically sound method would be to assess molecular markers for chemoresistance using conventional methods to aid in establishing a more effective regimen for patients. While many biomarkers have been implicated as potential candidates for resistance to anticancer agents, the research on these remains minimal, especially with regard to HNSCC.

We previously reported the mRNA expression for several candidate markers of chemoresistance in HNSCC patients, and showed an association between EGFR and HER-2 expression and in vitro chemosensitivity using a histoculture drug response assay (HDRA) (3). Here, we aimed to identify biomarkers that significantly predict response to chemotherapy in HNSCC patients by examining multigene mRNA expression in pretreatment biopsy specimens from HNSCC patients who were scheduled to undergo induction chemotherapy with 5-FU and cisplatin.

\section{Patients and methods}

Patient selection. Sixty-four patients who underwent radical treatment for HNSCC at the Department of Head and Neck Surgery, Aichi Cancer Center, Japan were enrolled in this study. The study protocol was approved by the Ethics Committees of the Aichi Cancer Center. Informed consent for participation in this study was obtained from all patients.

Treatment plan. All enrolled patients received induction chemotherapy with 5-FU and cisplatin before definitive therapy to select patients for organ preservation. For the recently treated arm, 35 patients $(54.7 \%)$ received continuous infusion of 5-FU $800 \mathrm{mg} / \mathrm{m}^{2} /$ day for 5 days followed by cisplatin $80 \mathrm{mg} / \mathrm{m}^{2}$ on day 6 , repeated every 3 weeks. For the previously treated arm, 27 patients $(42.2 \%)$ received continuous infusion of 5-FU $600 \mathrm{mg} / \mathrm{m}^{2} /$ day for 6 days followed by cisplatin $80 \mathrm{mg} / \mathrm{m}^{2}$ on day 7 , repeated every 3 weeks. Two patients (3.1\%) with poor renal function received cisplatin $25 \mathrm{mg} / \mathrm{m}^{2}$ on day 1 followed by continuous infusion of $5-\mathrm{FU} 1,000 \mathrm{mg} / \mathrm{m}^{2} /$ day for 2 days (day 1-2), repeated every week. Tumor responses were evaluated in accordance with the Response Evaluation Criteria In Solid Tumor Guidelines (RECIST) (4) after induction chemotherapy using head and neck computed tomography (CT) followed by biopsy with histopathological diagnosis. Responders of induction therapy then received definitive radiotherapy or concurrent chemoradiotherapy for organ preservation, while non-responders were treated with surgery.
Molecular assessment. Tumor biopsy samples were obtained before administration of induction chemotherapy. The samples were assessed for the mRNA expressions of 22 candidate predictive biomarkers (Table I). We subsequently investigated the association between the mRNA expression levels of the biomarkers and response to induction chemotherapy with $5 \mathrm{FU} /$ cisplatin.

RNA extraction and cDNA synthesis. Tumor tissue samples, obtained immediately after biopsy, were submerged in liquid nitrogen and stored at $-80^{\circ} \mathrm{C}$ for subsequent quantification of mRNA expression. Total RNA was isolated by a single-step guanidinium isothiocyanate-phenol-chloroform-based method using the ISOGEN RNA extraction kit (Nippon Gene, Inc., Tokyo, Japan) according to the manufacturer's instructions. After RNA isolation, cDNA was synthesized using the ThermoScript ${ }^{\mathrm{TM}}$ real-time polymerase chain reaction (RT-PCR) System (Invitrogen, Carlsbad, CA, USA) and $1 \mu \mathrm{g}$ of total RNA primed with oligo dT primer (Invitrogen), as described previously (3).

Reverse transcription-quantitative polymerase chain reaction (RT-qPCR) quantification. mRNA levels of each gene were measured by RT-PCR based on TaqMan chemistry and quantified using an ABI PRISM 7900-HT Sequence Detection System (Applied Biosystems, Foster City, CA, USA), as described previously (3). PCR reactions $(25 \mu \mathrm{l})$ were conducted in a 96-well plate. Reaction mixtures consisted of TaqMan Universal PCR Master mix (Applied Biosystems), forward and reverse primers (900 $\mathrm{nM}$ each), probe $(250 \mathrm{nM})$, and cDNA template (equal to $1 \mathrm{ng}$ total RNA). Reactions were performed at $50^{\circ} \mathrm{C}$ for $2 \mathrm{~min}$ and $95^{\circ} \mathrm{C}$ for $10 \mathrm{~min}$, then 55 cycles at $95^{\circ} \mathrm{C}$ for $15 \mathrm{sec}$ and $60^{\circ} \mathrm{C}$ for $1 \mathrm{~min}$. Gene expression analysis was performed in duplicate in the same PCR experiment. The primer and probe sequences used are summarized in Table I. To examine gene expression levels across the different tumor samples, we compared the relative expression level to that of a calibrator using the comparative $\mathrm{C}_{\mathrm{T}}$ method. The threshold cycle $\left(\mathrm{C}_{\mathrm{T}}\right)$ was defined as the fractional cycle number at which the fluorescence generated by cleavage of the probe exceeded a fixed threshold level above baseline. We normalized the amount of total RNA present in each reaction by amplifying the housekeeping gene GAPDH. The mRNA amount in tissue normalized to GAPDH mRNA was expressed as follows: $-\Delta \mathrm{C}_{\mathrm{T}}=-\left[\mathrm{C}_{\mathrm{T} \text { target }}-\mathrm{C}_{\mathrm{T} \text { GAPDH }}\right]$. The ratio of the amount of target mRNA to the amount of GAPDH mRNA was determined from $2^{-\Delta \mathrm{CT}} \times \mathrm{K}$, where $\mathrm{K}$ is a constant.

Statistical analysis. The covariates of interest were gender (male vs. female), age, T-class, N-class, and mRNA expression level (continuous variables). While mRNA levels were not normally distributed, the log-transformed levels fit a normal distribution (5). The outcome of interest was the response to induction chemotherapy. Student's t test was used to analyze correlations between the variables and response to induction chemotherapy. Variable selection with the entry and removal criterion $\mathrm{P}<0.05$ was used to construct a multivariate logistic regression analysis based on factors identified using univariate analysis. The odds ratios $(\mathrm{OR})$ and $95 \%$ confidence interval (CI) were calculated from the logistic regression models for predictors of response. 
Kaplan-Meier curves were used to compare differences in survival calculated using the log-rank test. Survival end points included overall survival and disease-free survival; overall survival considered all deaths as events while disease-free survival was defined as the time to recurrence. All statistical analyses were performed using EZR version 1.34 (6). A P-value $\leq 0.05$ was considered statistically significant.

\section{Results}

Patient population. The characteristics of this study population are summarized in Table II. Fifty patients $(78.1 \%)$ were male and 14 (21.9\%) were female with an age range of 31 to 79 years. The primary sites of cancer were the oropharynx $(\mathrm{n}=30 ; 46.9 \%)$ and hypopharynx $(\mathrm{n}=34 ; 53.1 \%)$. According to the Union for International Cancer Control (UICC) TNM classification, tumors were classified as T1/T2, T3/T4, N0 and N1-3 in 37 (57.8\%), 27 (42.2\%), 14 (21.9\%), and 50 patients (78.1\%), respectively. There were $8(12.5 \%), 11(17.2 \%)$ and 45 patients $(70.3 \%)$ with Stage II, III, and IV cancer, respectively. Twenty-one patients (32.8\%) showed CR after induction chemotherapy.

Association between survival and chemotherapy response. Survival curves according to response to induction chemotherapy are shown in Figs. 1 and 2. The CR group included 21 patients (32.8\%), while the non-CR group for induction chemotherapy comprised 43 patients $(67.2 \%)$. CR rates of three cisplatin/5-FU arms were $37 \%$ (13/35) in recently treated arm, $30 \%(18 / 27)$ in previously treated arm and $0 \%(0 / 2)$ in weekly arm, respectively. There was no significance among three arms in chi-square test.

The CR group received definitive radiotherapy or concurrent chemoradiotherapy after induction chemotherapy for organ preservation. The non-CR group was treated with radical surgery. The 5-year overall survival rate was 95 and $57 \%$, while the 5-year disease-free survival rate was 90 and $53 \%$ for the CR group non-CR group, respectively. The CR group for induction chemotherapy demonstrated significantly better prognoses than the non-CR group for overall $(\mathrm{P}=0.0009)$ and disease-free $(\mathrm{P}=0.0141)$ survival.

Chemotherapy response and gene expression. Patient response to induction chemotherapy for primary tumors was compared to tumor characteristics and gene expression (Tables III and IV). Univariate analysis using Student's t test demonstrated that a patient's clinical T-class was the only significant variable among the clinical factors $(\mathrm{P}=0.0002)$, indicating that $\mathrm{T} 1 / \mathrm{T} 2$ tumors were associated with increased chemotherapy response. Response to induction chemotherapy was significantly correlated with the log-transformed mRNA expression levels of ERCC1 ( $\mathrm{P}=0.0054)$, XPA $(\mathrm{P}=0.0154)$, p53 ( $\mathrm{P}=0.0092)$, DPD ( $\mathrm{P}=0.0274), \mathrm{Bcl}-2(\mathrm{P}=0.0135)$, VEGF $(\mathrm{P}=0.0213)$, and MDR1 $(\mathrm{P}=0.0389)$. Interestingly, high expression levels of these genes were significantly associated with increased sensitivity to chemotherapy. Multivariate logistic regression analysis was conducted using significant variables identified in the univariate model. ERCC1 expression (OR, 36; 95\% CI, 1-1100; $\mathrm{P}=0.040)$ and clinical T-class (OR, 0.119; 95\% CI, 0.022-0.637; $\mathrm{P}=0.013$ ) were identified as independent

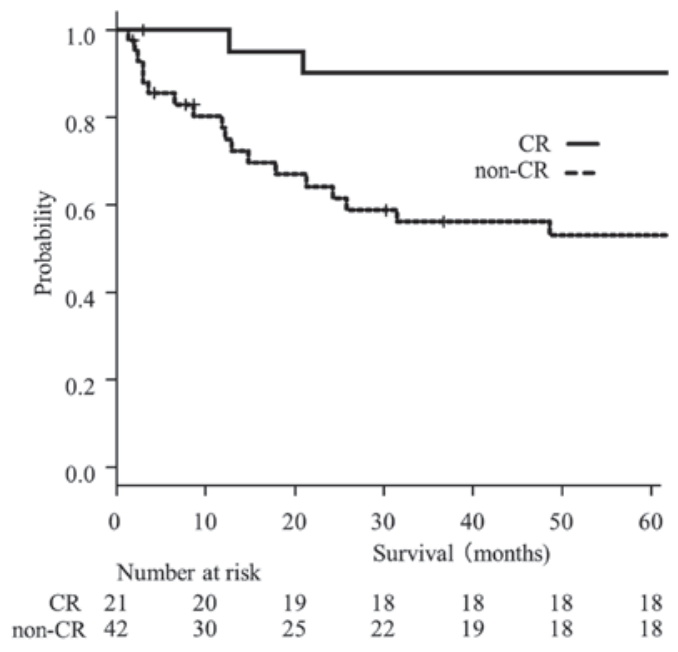

Figure 1. Kaplan-Meier curves indicating disease-free survival. The CR group includes patients with complete response or good partial response for induction chemotherapy. The non-CR group includes all other patients. CR, complete response.

predictors of response to combination chemotherapy with 5-FU/cisplatin.

\section{Discussion}

Platinum-based induction chemotherapy has been integral to comprehensive therapies for patients with HNSCC. Recently, many studies have focused on induction chemotherapy to assess both organ preservation and survival, demonstrating its encouraging potential as a novel therapeutic approach in HNSCC. Response to induction chemotherapy also allows for the predictive identification of patients who may respond to subsequent radiotherapy, and can help select patients for organ preservation. In the current study, $32.8 \%$ of patients showed CR after induction chemotherapy and were selected to undergo definitive radiotherapy or concurrent chemoradiotherapy for organ preservation. Patients who had good response to induction chemotherapy also showed significantly longer survival for both overall and disease-free survival than non-responders.

Intrinsic drug resistance and acquired resistance are critical factors for the efficacy of chemotherapeutic agents. Identifying molecular predictors of chemotherapy efficacy can provide important tools for designing individualized treatment regimens. We therefore investigated the association between gene expression and response to induction chemotherapy with 5-FU and cisplatin. Although newer regimens, such as paclitaxel or docetaxel plus cisplatin or carboplatin, have been extensively studied $(7,8)$, the combination chemotherapy of 5-FU and cisplatin remains the gold standard regimen in HNSCC.

5-FU is converted to the three main active metabolites fluorodeoxyuridine monophosphate, fluorodeoxyuridine triphosphate, and fluorouridine triphosphate via the enzymes thymidylate synthase (TS), orotate phosphoribosyltransferase (OPRT), tymidine phosphorylase (TP), and dihydropyrimidine dehydrogenase (DPD) $(9,10)$. Therefore, a large number of studies have focused on assessing the expressions of TS, OPRT, 


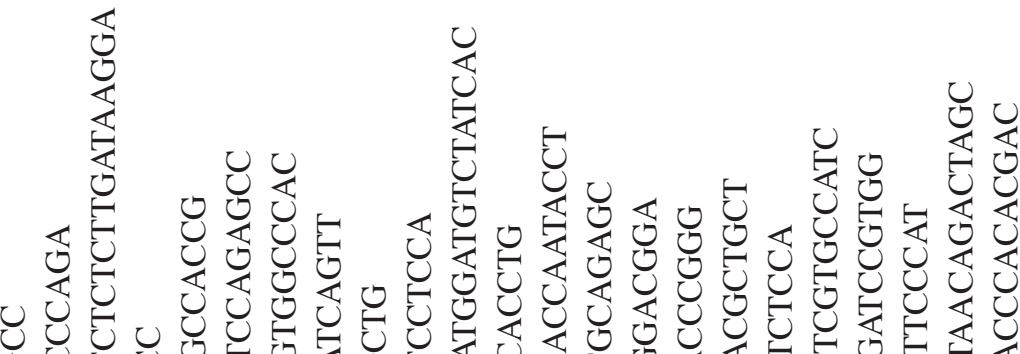

$\bigcup_{\mho}$

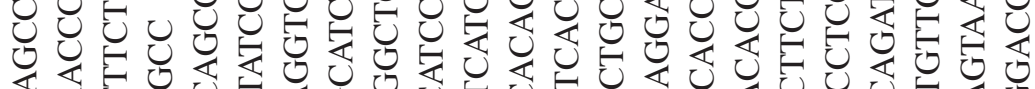

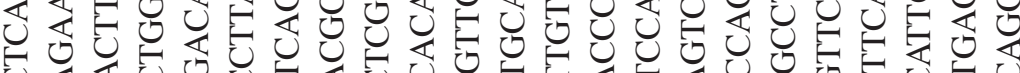

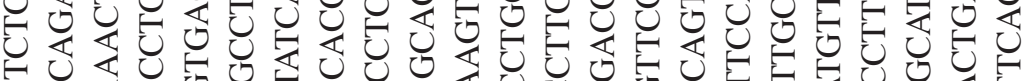

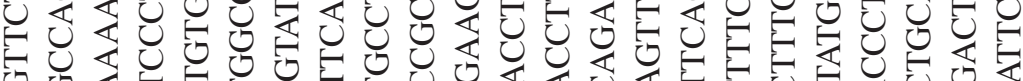

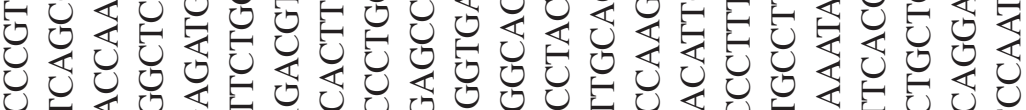

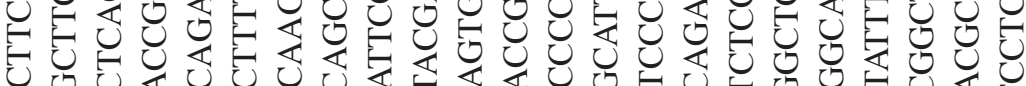

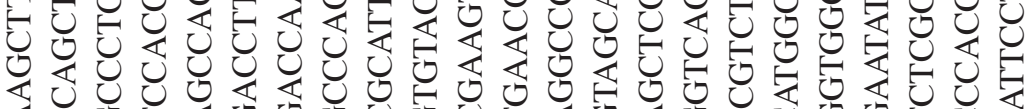

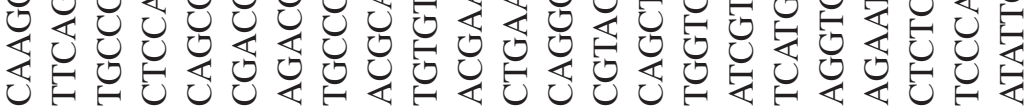

还荙 导出

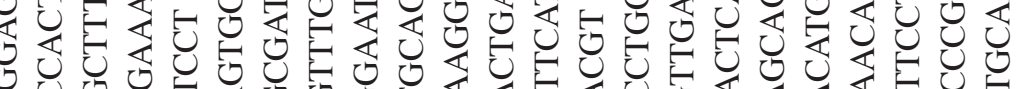

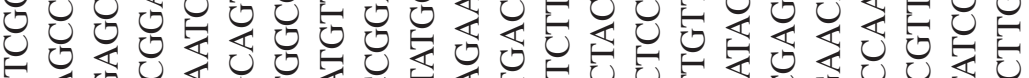

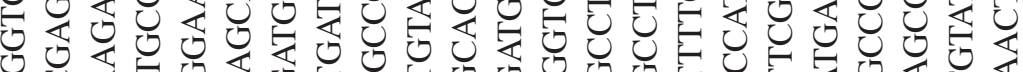
O

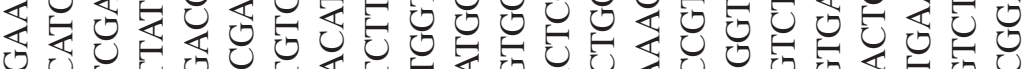

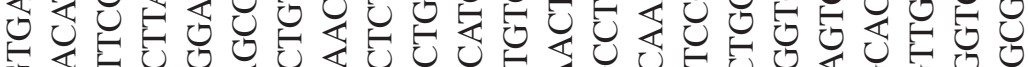

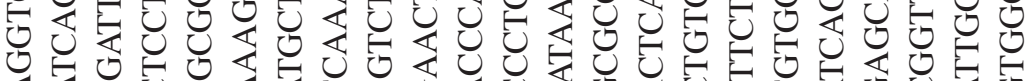

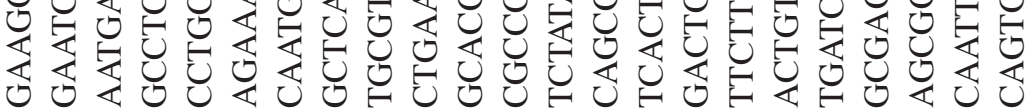

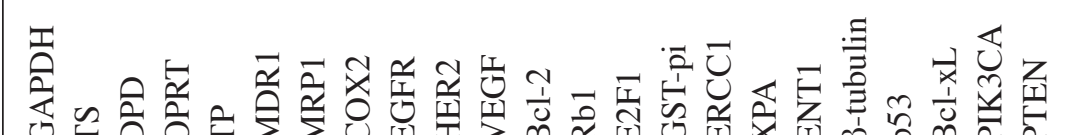


Table II. Patient characteristics.

\begin{tabular}{|c|c|}
\hline & $\begin{array}{c}\text { No. of patients } \\
n=64(\%)\end{array}$ \\
\hline \multicolumn{2}{|l|}{ Sex } \\
\hline Male & $50(78.1)$ \\
\hline Female & $14(21.9)$ \\
\hline \multicolumn{2}{|l|}{ Age, years } \\
\hline Range & $31-79$ \\
\hline Median & 61 \\
\hline \multicolumn{2}{|l|}{ Site } \\
\hline Oropharynx & $30(46.9)$ \\
\hline Hypopharynx & $34(53.1)$ \\
\hline \multicolumn{2}{|l|}{ Tumor status } \\
\hline $\mathrm{T} 1$ & $3(4.7)$ \\
\hline $\mathrm{T} 2$ & $34(53.1)$ \\
\hline $\mathrm{T} 3$ & $19(29.7)$ \\
\hline $\mathrm{T} 4$ & $8(12.5)$ \\
\hline \multicolumn{2}{|l|}{ Node status } \\
\hline N0 & $14(21.9)$ \\
\hline N1 & $6(9.4)$ \\
\hline N2 & $37(57.8)$ \\
\hline N3 & $7(10.9)$ \\
\hline \multicolumn{2}{|l|}{ Stage } \\
\hline I & $0(0)$ \\
\hline II & $8(12.5)$ \\
\hline III & $11(17.2)$ \\
\hline IV & $45(70.3)$ \\
\hline \multicolumn{2}{|l|}{ Chemo-respnse } \\
\hline CR & $21(32.8)$ \\
\hline Non-CR & $43(67.2)$ \\
\hline
\end{tabular}

CR, complete response.

TP, and DPD as key enzymes for the regulation 5-FU resistance. We showed that only DPD expression was significantly associated with response to chemotherapy, with higher DPD expression correlating with enhanced response to 5-FU/cisplatin. A previous study showed that DPD was the first key enzyme linked to 5-FU catabolism, and that it was predictive of 5-FU responsiveness in HNSCC (11). Overexpression of DPD is also associated with resistance to 5-FU in head and neck and colorectal cancer $(11,12)$. In contrast, however, another study demonstrated that heterogeneity, rather than intensity, of DPD expression regulated 5-FU sensitivity in oral SCC (13). While many studies have reported a correlation between high DPD expression levels and chemoresistance or poor survival rate, the prognostic value of DPD expression is still controversial in induction chemotherapy with 5-FU/cisplatin. Further studies that assess DPD levels using an enzyme assay or that examine the modification of molecular structures caused by mutations, as a previous study indicated (14), may clarify a potential role for DPD as a marker for response to induction chemotherapy with 5-FU/cisplatin.

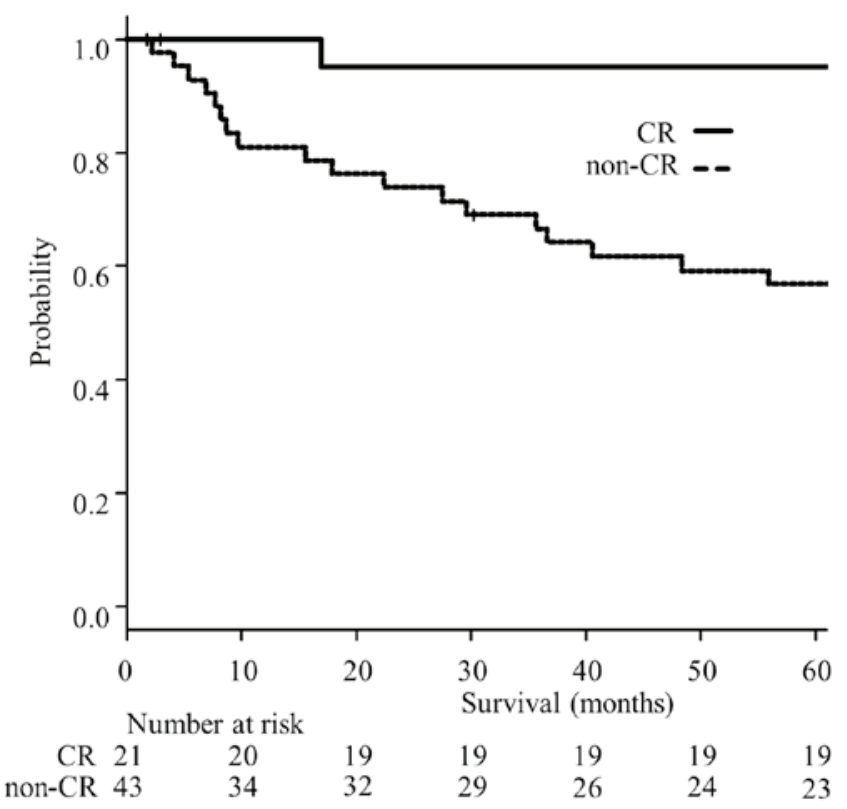

Figure 2. Kaplan-Meier curves indicating overall survival. CR, complete response.

The cytotoxic mode of action of cisplatin is mediated by its interaction with DNA to form DNA adducts, primarily intrastrand crosslink adducts. After binding to DNA, cisplatin inhibits replication and leads to arrest in the G2 phase of the cell cycle, resulting in apoptosis. Cisplatin resistance appears to be associated with several molecular alterations, including drug detoxification, upregulation of DNA repair enzymes, overexpression of anti-apoptotic proteins, and detoxifying enzymes (15-17). Based on their mechanisms for effecting cancer cells, 5-FU and cisplatin appear to be associated with distinct factors of drug resistance. However, reports indicate that tumors that fail to respond to cisplatin are cross-resistant to diverse unrelated anticancer agents, suggesting that cisplatin likely shares common mechanisms of resistance with other agents (18).

Nucleotide excision repair (NER) is a highly conserved mechanism that repairs DNA-damaged lesions caused by platinum compounds (19). The basic steps in this pathway include DNA damage recognition and demarcation of the affected area, followed by formation of a complex to unwind the damaged DNA, excision of the DNA at the lesion site, removal of the damaged strand, and synthesis of new DNA that is complimentary to the remaining strand and ligation (15). Excision repair cross-complementing 1 (ERCC1) plays a key role in NER. ERCC1 dimerizes with xeroderma pigmentosum complementation group $\mathrm{F}$ to form a complex that is required for excising the damaged DNA (15). XPA is a protein involved in the initial damage recognition and recruitment stage of the NER pathway (20). A previous study investigating the contribution of the XPA-binding region of ERCC1 on NER activity showed that the interaction between ERCC1 and XPA was essential for NER (21). Evaluations of ERCC1 mRNA expression from various types of cancers have shown an inverse correlation between response to platinum-based chemotherapy and survival in testicular, ovarian, colorectal, and non-small cell lung cancers (22-25). However, 
Table III. Univariate analysis of predictive factors for response to chemotherapy using Student's t test.

\begin{tabular}{|c|c|c|c|c|c|c|c|}
\hline \multirow[b]{3}{*}{ Markers } & \multirow[b]{3}{*}{ Variables } & \multirow[b]{3}{*}{ Scale } & \multicolumn{4}{|c|}{ Response } & \multirow[b]{3}{*}{ P-value } \\
\hline & & & \multicolumn{2}{|c|}{$\mathrm{CR}$} & \multicolumn{2}{|c|}{ nonCR } & \\
\hline & & & Mean & SD & Mean & SD & \\
\hline \multirow[t]{4}{*}{ Clinical } & Sex & Male/female & - & - & - & - & 0.3340 \\
\hline & Age & Year & 58.8196 & 7.2268 & 60.8125 & 11.1649 & 0.4600 \\
\hline & $\mathrm{T}$ class & T1-T4 & 2.0000 & 0.4472 & 2.7442 & 0.7896 & 0.0002 \\
\hline & $\mathrm{N}$ class & NO-N3 & 1.6667 & 0.7958 & 1.5349 & 1.0316 & 0.6090 \\
\hline \multirow[t]{22}{*}{ Biological } & $\mathrm{TS}$ & $\begin{array}{l}\text { Log-transformed } \\
\text { level of mRNA }\end{array}$ & -2.3916 & 0.8924 & -2.5538 & 0.5462 & 0.3720 \\
\hline & ERCC1 & & -1.2602 & 0.4269 & -1.5298 & 0.3092 & 0.0054 \\
\hline & XPA & & -1.1154 & 0.5074 & -1.4032 & 0.3943 & 0.0154 \\
\hline & p53 & & -1.0214 & 0.7949 & -1.5197 & 0.6446 & 0.0092 \\
\hline & $\mathrm{E} 2 \mathrm{~F} 1$ & & -1.4983 & 0.7463 & -1.7150 & 0.4665 & 0.1600 \\
\hline & $\mathrm{Rb} 1$ & & -1.7118 & 0.4796 & -1.8984 & 0.4409 & 0.1330 \\
\hline & PI3K & & -1.5902 & 0.5023 & -1.6718 & 0.3359 & 0.4490 \\
\hline & ENT1 & & -1.3960 & 0.5023 & -1.5197 & 0.3539 & 0.2590 \\
\hline & DPD & & -1.9756 & 0.4096 & -2.2797 & 0.5454 & 0.0274 \\
\hline & OPRT & & -0.9528 & 0.3762 & -1.1755 & 0.4763 & 0.0657 \\
\hline & $\mathrm{TP}$ & & -0.4993 & 0.4881 & -0.5135 & 0.4294 & 0.9060 \\
\hline & Bcl-2 & & -2.1529 & 0.6099 & -2.6697 & 0.8028 & 0.0135 \\
\hline & Bcl-xL & & -0.8639 & 1.0317 & -1.0097 & 0.6018 & 0.4780 \\
\hline & PTEN & & -1.2380 & 0.5045 & -1.3281 & 0.4101 & 0.4470 \\
\hline & VEGF & & -1.1783 & 0.3474 & -1.4444 & 0.4550 & 0.0213 \\
\hline & $\mathrm{COX} 2$ & & -1.6233 & 0.7336 & -1.8537 & 0.6593 & 0.2110 \\
\hline & EGFR & & -1.6129 & 0.6780 & -1.7037 & 0.5523 & 0.5690 \\
\hline & HER2 & & -0.8955 & 0.5601 & -1.0512 & 0.4565 & 0.2390 \\
\hline & MDR1 & & -2.6895 & 0.7712 & -3.1987 & 0.9235 & 0.0389 \\
\hline & MRP1 & & -1.1319 & 0.5547 & -1.2508 & 0.5677 & 0.4310 \\
\hline & GST-pi & & 0.3794 & 0.3245 & 0.2560 & 0.3598 & 0.1890 \\
\hline & $\beta$-tubulin & & -0.3397 & 0.3344 & -0.3311 & 0.2673 & 0.9110 \\
\hline
\end{tabular}

Bold print denotes significant values and variables.

Table IV. Multivariate analysis of predictive factors for response to chemotherapy using logistic regression.

\begin{tabular}{|c|c|c|c|c|c|c|}
\hline \multirow[b]{2}{*}{ Markers } & \multirow[b]{2}{*}{ Variables } & \multirow[b]{2}{*}{ Scale } & \multirow[b]{2}{*}{ Odds ratio } & \multicolumn{2}{|c|}{$95 \% \mathrm{CI}$} & \multirow[b]{2}{*}{ P-value } \\
\hline & & & & Lower & Upper & \\
\hline Clinical & $\mathbf{T}$ class & $\mathrm{T} 1-\mathrm{T} 4$ & 0.119 & 0.022 & 0.637 & 0.013 \\
\hline \multirow[t]{7}{*}{ Biological } & ERCC1 & $\begin{array}{l}\text { Log-transformedl } \\
\text { level of mRNA }\end{array}$ & 36 & 1 & 1,100 & 0.040 \\
\hline & XPA & & 0.570 & 0.047 & 6.930 & 0.659 \\
\hline & p53 & & 2.160 & 0.657 & 7.070 & 0.205 \\
\hline & DPD & & 0.546 & 0.107 & 2.770 & 0.465 \\
\hline & $\mathrm{Bcl}-2$ & & 1.020 & 0.222 & 4.660 & 0.981 \\
\hline & VEGF & & 0.683 & 0.094 & 4.990 & 0.707 \\
\hline & MDR1 & & 1.800 & 0.464 & 6.960 & 0.397 \\
\hline
\end{tabular}

Bold print denotes significant values and variables. 
we found a significant correlation between high expressions of ERCC1 and XPA and increased response to chemotherapy in HNSCC. Increased ERCC1 expression has been shown to be correlated with improved outcomes in gastric cancer patients (26). Overexpression of ERCC1 has also been shown to improve treatment outcomes in lung cancer patients (27). Further, a clinical study demonstrated that reduced DNA repair capacity increases the risk of developing lung cancer (28). Interestingly, a recent study showed that a defect in the interaction between ERCC1 and XPA that disrupts NER has no major effect on cellular sensitivity to cisplatin, suggesting that ERCC1-mediated NER is not a key determinant of cellular sensitivity to cisplatin (21). While a large number of studies have demonstrated that lower ERCC1 expression is associated with increased response to platinum-based chemotherapy and survival $(15,29)$, DNA damage is known to be associated with an increased risk of cancers in which reduced DNA repair capacity may accelerate the alteration and mutation of essential genes, causing carcinogenesis. Therefore, the reduced DNA repair capacity of ERCC1 and XPA may not always result in increased response to chemotherapy, particularly in patients in which cancer progression is caused by low ERCC1 or XPA expression. Because the DNA repair pathway is a markedly complex process involving NER, mismatch repair, base excision repair, and gene-specific repair, previous studies have suggested that regulation of the efficacy of chemotherapeutic agents is not likely to only comprise a simple mechanism in which the NER pathway and apoptotic pathways are linked in a complFex (24). Further studies are needed to clarify the mechanisms of the NER pathway, such as by identifying the associated gene polymorphisms and mutations.

p53, a tumor suppressor gene, is an essential regulator of apoptosis and a well-known regulatory gene for cisplatin resistance. When DNA damage occurs in cells, increased levels of active p53 induce either G1 cell cycle arrest or apoptosis followed by suppression of tumorigenesis (30). p53 mutations occur in $40-70 \%$ of HNSCC patients, leading to extensive research on wild-type p53 as a potential therapeutic target (30). Previous reports have indicated that overexpression of the p53 protein in tumor cells is strongly associated with chemotherapy response and larynx preservation $(31,32)$. High expression of wild-type p53 was also shown to be important for apoptotic cell death in cisplatin-treated cells (33). In agreement with these previous findings, we found that high expression of p53 was correlated with response to chemotherapy.

Expression of $\mathrm{Bcl}-2$ is upregulated in various types of tumors. Many studies have reported a significantly worse treatment outcome in patients with high $\mathrm{Bcl}$-2-expressing tumors (34). An important function of Bcl-2 is to inhibit apoptosis induced by radiation and chemotherapeutic agents (35). While we found that overexpression of Bcl-2 was associated with good chemotherapy response, we could not verify the mechanism of action. One of several studies that identified a correlation between Bcl-2 expression and a favorable outcome also showed that local control probability was significantly improved for patients with Bcl-2-expressing tumors treated by radiotherapy (36). High expression of $\mathrm{Bcl}-2$ has also been reported to be a good prognostic indicator in breast cancer, which supports our findings (37). Expressions of other Bcl-2 family members, which are primary regulators of apoptosis, may affect the function of Bcl-2 $(38,39)$.

The role of Bcl-2 as a proangiogenic signaling molecule for both tumor and vascular endothelial cells is well established (39). Previous studies have shown that stimulation of the VEGF signaling pathway results in increased expression of Bcl-2 in tumor and endothelial cells (40). Moreover, Bcl-2 expression is significantly upregulated in HNSCC-associated endothelial cells compared to endothelial cells in normal oral mucosa, and Bcl-2 induces VEGF expression in neovascular endothelial cells through a STAT3-mediated pathway (41). We observed a significant association between chemotherapy response and VEGF expression, suggesting that the VEGF-Bcl-2 pathway may be important for patient response to anticancer agents in head and neck cancer.

Multidrug resistance gene 1 (MDR1) functions as an ATP-dependent pump that transports foreign substances out of cells, including anticancer drugs $(42,43)$. Previous studies have demonstrated that cisplatin enhanced MDR1 expression and its function, resulting in drug resistance in cancer cells, even though cisplatin is not a substrate for MDR1 $(42,44)$. Interestingly, rather than an association between high MDR1 expression and resistance to chemotherapy, we found a correlation between high MDR1 expression and chemosensitivity. MDR1 expression in tumor cells is increased following each course of chemotherapy, leading to enhanced resistance to anticancer agents (44). Therefore, changes in the expression of MDR1 prior to and following induction chemotherapy should be measured in the present set of patients to verify whether sequential changes in expression are associated with chemotherapy response.

In summary, we showed that ERCC1 expression and T-class were independent predictors of response to induction chemotherapy using 5-FU and cisplatin. In a meta-analysis of 1,288 HNSCC patients receiving platinum-based therapy, Bišof et al reported that ERCC1 may be a predictive and prognostic factor for individualized therapies for HNSCC patients (45). Our findings also suggest that ERCC1 may be a predictive biomarker for response to chemotherapy with 5-FU/cisplatin in HNSCC patients. A DNA repair pathway and an apoptosis pathway are pivotal to the mechanism underlying response to chemotherapy. Although efficient DNA repair activity inhibits cancer cell progression and invasion via apoptosis signaling, it might be potentially disadvantageous for response to anticancer agents. While assessing mRNA expression is a standard method for these studies, the mechanisms underlying drug resistance are complex and require additional investigation. Further studies examining ERCC1 polymorphisms and mutations and assessing apoptotic response associated with p53 activation in HNSCC are needed to clarify genetic associations with response to chemotherapy in HNSCC patients.

\section{Acknowledgements}

The present study was supported in part by a grant from the Aichi Cancer Research Foundation. The authors thank Ms. Midori Maeda for her excellent technical assistance, and the editors at DMC Corp. for editing drafts of the present study. 


\section{References}

1. Lefebvre JL, Chevalier D, Luboinski B, Kirkpatrick A, Collette L and Sahmoud: Larynx preservation in pyriform sinus cancer: Preliminary results of a European Organization for Research and Treatment of Cancer phase III trial. EORTC Head and Neck Cancer Cooperative Group. J Natl Cancer Inst 88: 890-899, 1996.

2. Paccagnella A, Orlando A, Marchiori C, Zorat PL, Cavaniglia G, Sileni VC, Jirillo A, Tomio L, Fila G, Fede A, et al: Phase III trial of initial chemotherapy in stage III or IV head and neck cancers: A study by the Gruppo di Studio sui Tumori della Testa e del Collo. J Natl Cancer Inst 86: 265-272, 1994.

3. Hasegawa Y, Goto M, Hanai N, Ijichi K, Terada A, Hyodo I, Ogawa T and Fukushima M: Prediction of chemosensitivity using multigene analysis in head and neck squamous cell carcinoma. Oncology 73: 104-111, 2007.

4. Therasse P, Arbuck SG, Eisenhauer EA, Wanders J, Kaplan RS, Rubinstein L, Verweij J, Van Glabbeke M, van Oosterom AT, Christian MC and Gwyther SG: New guidelines to evaluate the response to treatment in solid tumors. European Organization for Research and Treatment of Cancer, National Cancer Institute of the United States, National Cancer Institute of Canada. J Natl Cancer Inst 92: 205-216, 2000

5. Oze I, Shimada S, Nagasaki H, Akiyama Y, Watanabe M, Yatabe Y, Matsuo K and Yuasa Y: Plasma microRNA-103, microRNA-107 and microRNA-194 levels are not biomarkers for human diffuse gastric cancer. J Cancer Res Clin Oncol 143: 551-554, 2017.

6. Kanda Y: Investigation of the freely available easy-to-use software 'EZR' for medical statistics. Bone Marrow Transplant 48: 452-458, 2013

7. Posner MR, Hershock DM, Blajman CR, Mickiewicz E, Winquist E, Gorbounova V, Tjulandin S, Shin DM, Cullen K, Ervin TJ, et al: Cisplatin and fluorouracil alone or with docetaxel in head and neck cancer. N Engl J Med 357: 1705-1715, 2007.

8. Vermorken JB, Remenar E, van Herpen C, Gorlia T, Mesia R, Degardin M, Stewart JS, Jelic S, Betka J, Preiss JH, et al: Cisplatin, fluorouracil, and docetaxel in unresectable head and neck cancer. N Engl J Med 357: 1695-1704, 2007.

9. Kodera Y, Ito S, Fujiwara M, Mochizuki Y, Nakayama G, Ohashi N, Koike M, Yamamura Y and Nakao A: Gene expression of 5-fluorouracil metabolic enzymes in primary gastric cancer: Correlation with drug sensitivity against 5 -fluorouracil. Cancer Lett 252: 307-313, 2007.

10. Sameshima S, Tomozawa S, Horikoshi H, Motegi K, Hirayama I, Koketsu S, Okada T, Kojima M, Kon Y and Sawada T: 5-Fluorouracil-related gene expression in hepatic artery infusion-treated patients with hepatic metastases from colorectal carcinomas. Anticancer Res 28: 389-393, 2008.

11. Etienne MC, Chéradame S, Fischel JL, Formento $P$, Dassonville O, Renée N, Schneider M, Thyss A, Demard F and Milano G: Response to fluorouracil therapy in cancer patients: The role of tumoral dihydropyrimidine dehydrogenase activity. J Clin Oncol 13: 1663-1670, 1995.

12. Salonga D, Danenberg KD, Johnson M, Metzger R, Groshen S, Tsao-Wei DD, Lenz HJ, Leichman CG, Leichman L, Diasio RB, et al: Colorectal tumors responding to 5-fluorouracil have low gene expression levels of dihydropyrimidine dehydrogenase, thymidylate synthase, and thymidine phosphorylase. Clin Cancer Res 6: 1322-1327, 2000.

13. Kobayashi H, Koike T, Nakatsuka A, Kurita H, Sagara J, Taniguchi S and Kurashina K: Dihydropyrimidine dehydrogenase expression predicts survival outcome and chemosensitivity to 5-fluorouracil in patients with oral squamous cell carcinoma Oral Oncol 41: 38-47, 2005.

14. Calascibetta A, Contino F, Feo S, Gulotta G, Cajozzo M, Antona A, Sanguedolce G and Sanguedolce R: Analysis of the thymidylate synthase gene structure in colorectal cancer patients and its possible relation with the 5-Fluorouracil drug response. J Nucleic Acids 2010: pii: 306754, 2010.

15. Martin LP, Hamilton TC and Schilder RJ: Platinum resistance: The role of DNA repair pathways. Clin Cancer Res 14: 1291-1295, 2008

16. Kartalou M and Essigmann JM: Mechanisms of resistance to cisplatin. Mutat Res 478: 23-43, 2001.

17. Crul M, Schellens JH, Beijnen JH and Maliepaard M: Cisplatin resistance and DNA repair. Cancer Treat Rev 23: 341-366, 1997.
18. Ozols RF: Chemotherapy for advanced epithelial ovarian cancer. Hematol Oncol Clin North Am 6: 879-894, 1992.

19. Rabik CA and Dolan ME: Molecular mechanisms of resistance and toxicity associated with platinating agents. Cancer Treat Rev 33: 9-23, 2007.

20. McGurk CJ, Cummings M, Köberle B, Hartley JA, Oliver RT and Masters JR: Regulation of DNA repair gene expression in human cancer cell lines. J Cell Biochem 97: 1121-1136, 2006.

21. Orelli B, McClendon TB, Tsodikov OV, Ellenberger T, Niedernhofer LJ and Schärer OD: The XPA-binding domain of ERCC1 is required for nucleotide excision repair but not other DNA repair pathways. J Biol Chem 285: 3705-3712, 2010.

22. Welsh C, Day R, McGurk C, Masters JR, Wood RD and Köberle B: Reduced levels of XPA, ERCC1 and XPF DNA repair proteins in testis tumor cell lines. Int J Cancer 110: 352-361, 2004

23. Dabholkar M, Bostick-Bruton F, Weber C, Bohr VA, Egwuagu C and Reed E: ERCC1 and ERCC2 expression in malignant tissues from ovarian cancer patients. J Natl Cancer Inst 84: 1512-1517, 1992.

24. Shirota Y, Stoehlmacher J, Brabender J, Xiong YP, Uetake H, Danenberg KD, Groshen S, Tsao-Wei DD, Danenberg PV and Lenz HJ: ERCC1 and thymidylate synthase mRNA levels predict survival for colorectal cancer patients receiving combination oxaliplatin and fluorouracil chemotherapy. J Clin Oncol 19: 4298-4304, 2001

25. Lord RV, Brabender J, Gandara D, Alberola V, Camps C, Domine M, Cardenal F, Sánchez JM, Gumerlock PH Tarón M, et al: Low ERCC1 expression correlates with prolonged survival after cisplatin plus gemcitabine chemotherapy in non-small cell lung cancer. Clin Cancer Res 8: 2286-2291, 2002.

26. Kim JS, Kim MA, Kim TM, Lee SH, Kim DW, Im SA, Kim TY, Kim WH, Yang HK, Heo DS, et al: Biomarker analysis in stage III-IV (M0) gastric cancer patients who received curative surgery followed by adjuvant 5-fluorouracil and cisplatin chemotherapy: Epidermal growth factor receptor (EGFR) associated with favourable survival. Br J Cancer 100: 732-738, 2009.

27. Lee KH, Min HS, Han SW, Oh DY, Lee SH, Kim DW, Im SA, Chung DH, Kim YT, Kim TY, et al: ERCC1 expression by immunohistochemistry and EGFR mutations in resected non-small cell lung cancer. Lung Cancer 60: 401-407, 2008.

28. Wei Q, Cheng L, Hong WK and Spitz MR: Reduced DNA repair capacity in lung cancer patients. Cancer Res 56: 4103-4107, 1996.

29. Xuelei M, Jingwen H, Wei D, Hongyu Z, Jing Z, Changle S and Lei L: ERCC1 plays an important role in predicting survival outcomes and treatment response for patients with HNSCC: A meta-analysis. Oral Oncol 51: 483-492, 2015.

30. Moon C, Oh Y and Roth JA: Current status of gene therapy for lung cancer and head and neck cancer. Clin Cancer Res 9: 5055-5067, 2003

31. Bradford CR, Wolf GT, Carey TE, Zhu S, Beals TF, Truelson JM, McClatchey KD and Fisher SG: Predictive markers for response to chemotherapy, organ preservation, and survival in patients with advanced laryngeal carcinoma. Otolaryngol Head Neck Surg 121: 534-538, 1999.

32. Bradford CR, Zhu S, Wolf GT, Poore J, Fisher SG, Beals T, McClatchey KD and Carey TE: Overexpression of $\mathrm{p} 53$ predicts organ preservation using induction chemotherapy and radiation in patients with advanced laryngeal cancer. Department of Veterans Affairs Laryngeal Cancer Study Group. Otolaryngol Head Neck Surg 113: 408-412, 1995

33. Yip HT, Chopra R, Chakrabarti R, Veena MS, Ramamurthy B, Srivatsan ES and Wang MB: Cisplatin-induced growth arrest of head and neck cancer cells correlates with increased expression of p16 and p53. Arch Otolaryngol Head Neck Surg 132: 317-326, 2006.

34. Friedman M, Grey P, Venkatesan TK, Bloch I, Chawla P, Caldarelli DD and Coon JS: Prognostic significance of Bcl-2 expression in localized squamous cell carcinoma of the head and neck. Ann Otol Rhinol Laryngol 106: 445-450, 1997.

35. Strasser A, Harris AW, Jacks T and Cory S: DNA damage can induce apoptosis in proliferating lymphoid cells via p53-independent mechanisms inhibitable by Bcl-2. Cell 79: 329-339, 1994.

36. Wilson GD, Grover R, Richman PI, Daley FM, Saunders MI and Dische S: Bcl-2 expression correlates with favourable outcome in head and neck cancer treated by accelerated radiotherapy. Anticancer Res 16: 2403-2408, 1996.

37. Hotz MA, Bosq J, Zbaeren P, Reed J, Schwab G, Krajewski S, Brousset P and Borner MM: Spontaneous apoptosis and the expression of p53 and $\mathrm{Bcl}-2$ family proteins in locally advanced head and neck cancer. Arch Otolaryngol Head Neck Surg 125: 417-422, 1999. 
38. van Delft MF and Huang DC: How the Bcl-2 family of proteins interact to regulate apoptosis. Cell Res 16: 203-213, 2006.

39. Zeitlin BD, Zeitlin IJ and Nör JE: Expanding circle of inhibition: Small-molecule inhibitors of Bcl-2 as anticancer cell and antiangiogenic agents. J Clin Oncol 26: 4180-4188, 2008.

40. Pidgeon GP, Barr MP, Harmey JH, Foley DA and Bouchier-Hayes DJ: Vascular endothelial growth factor (VEGF) upregulates BCL-2 and inhibits apoptosis in human and murine mammary adenocarcinoma cells. Br J Cancer 85: 273-278, 2001.

41. Kaneko T,Zhang Z, Mantellini MG, KarlE,Zeitlin B, Verhaegen M, Soengas MS, Lingen M, Strieter RM, Nunez G and Nör JE: Bcl-2 orchestrates a cross-talk between endothelial and tumor cells that promotes tumor growth. Cancer Res 67: 9685-9693, 2007.

42. Takara K, Tsujimoto M, Kokufu M, Ohnishi N and Yokoyama T: Up-regulation of MDR1 function and expression by cisplatin in LLC-PK1 cells. Biol Pharm Bull 26: 205-209, 2003.
43. Hoffmann AC, Wild P, Leicht C, Bertz S, Danenberg KD, Danenberg PV, Stöhr R, Stöckle M, Lehmann J, Schuler M and Hartmann A: MDR1 and ERCC1 expression predict outcome of patients with locally advanced bladder cancer receiving adjuvant chemotherapy. Neoplasia 12: 628-636, 2010.

44. Warmann S, Hunger M, Teichmann B, Flemming P, Gratz KF and Fuchs J: The role of the MDR1 gene in the development of multidrug resistance in human hepatoblastoma: Clinical course and in vivo model. Cancer 95: 1795-1801, 2002.

45. Bišof $V$, Zajc Petranović $M$, Rakušić Z, Samardžić KR and Juretić A: The prognostic and predictive value of excision repair cross-complementation group 1 (ERCC1) protein in 1288 patients with head and neck squamous cell carcinoma treated with platinum-based therapy: A meta-analysis. Eur Arch Otorhinolaryngol 273: 2305-2317, 2016. 